EPJ Web of Conferences 59, 19001 (2013)

DOI: $10.1051 /$ epjconf/20135919001

(C) Owned by the authors, published by EDP Sciences, 2013

\title{
Application of laser produced ion beams to nuclear analysis of materials
}

\author{
Kunioki Mima ${ }^{1,4,5}$, K. Fujita ${ }^{1}$, H. Azuma ${ }^{3}$, A. Yamazaki ${ }^{2}$, Y. Kato ${ }^{1}$, C. Okuda ${ }^{3}$, \\ Y. Ukyo ${ }^{3}$, H. Sawada ${ }^{3}$, Raquel Gonzalez-Arrabal ${ }^{4}$, J.M. Perlado ${ }^{4}$, \\ H. Nishimura ${ }^{5}$ and S. Nakai ${ }^{1}$
}

1 The Graduate School for the Creation of New Photonics Industries, 1955-1 Kurematsu Nishi-ku, Hamamatsu 431-1202, Japan

2 Takasaki Advanced Radiation Research Institute, Japan Atomic Energy Agency

3 Toyota Central R\&D Labs., Inc

4 Institute of Fusion Nuclear, Universidad Politecnica de Madrid, Cl Jose Gutierrez Abascal, 2, Madrid 28006, Spain

5 Institute of Laser Engineering, Osaka University, 2-6 Yamada-oka, Suita, Osaka 565-0817, Japan

\begin{abstract}
The ion beam driven nuclear analysis has been developed for many years by using various electrostatic accelerators. A proton micro-beam with the beam diameter of $\sim 1.5 \mu \mathrm{m}$ at Takasaki Ion Acceleration for Advanced Radiation Application (TIARA), JAEA was used to analyze the positive electrode of the Li-ion battery with PIGE and PIXE. WThe PIGE and PIXE images of Li and Ni respectively for $\mathrm{Li}_{\mathrm{x}} \mathrm{Ni}_{0.8} \mathrm{Co}_{0.15} \mathrm{Al}_{0.05} \mathrm{O}_{2}(\mathrm{x}=0.75 \sim 1.0)$ anodes have been taken. The PIGE images of $\mathrm{Li}_{\mathrm{x}} \mathrm{Ni}_{0.8} \mathrm{Co}_{0.15} \mathrm{Al}_{0.05} \mathrm{O}_{2}$ particles and the depth profile of the Li density have been obtained with high spatial resolution (a few $\mu \mathrm{m}$ ). The images of the Li density distribution are very useful for the $\mathrm{R} \& \mathrm{D}$ of the $\mathrm{Li}$ ion battery. In order to make the in-situ ion beam analysis of the Li battery possible, a compact accelerator for a high quality $\mathrm{MeV}$ proton beam is necessary. Form this point of view, the diagnostics of Li ion battery is an appropriate field for the applications of laser produced ion beams.
\end{abstract}

\section{INTRODUCTION}

Laser driven ion beams are interesting not only for their relative compactness, but also for their extraordinarily high beam qualities. Namely, the laser produced ion beams have high energy density, high brightness, short duration and so on [1-8]. Furthermore, laser produced ion beams have very low emittance [1, 2], [8]. These characteristics of the laser produced ion beams are advantageous as an ion beam for material analysis. Atomic and nuclear processes induced by the ion beams have been widely applied for the material analysis (see [9] for an example). There are several methods for nuclear material analysis: Rutherford Back Scattering (RBS), Elastic Recoil Spectroscopy (ERS), Particle Induced X-ray Emission (PIXE), Proton Induced Gamma-ray Emission (PIGE) [9-11], and so on.

For developing the advanced Li-ion battery, it is required to diagnose the Li density distribution in an electrode in charged and discharged states with micrometer spatial resolution. The above ion beam nuclear material analysis is a powerful tool for observing light elements because cross sections of proton induced nuclear processes for light elements are comparable to or higher than those for heavy elements. As an example, PIGE images of Li and PIXE images of Ni density distributions can be obtained to find

This is an Open Access article distributed under the terms of the Creative Commons Attribution License 2.0, which permits unrestricted use, distribution, and reproduction in any medium, provided the original work is properly cited. 


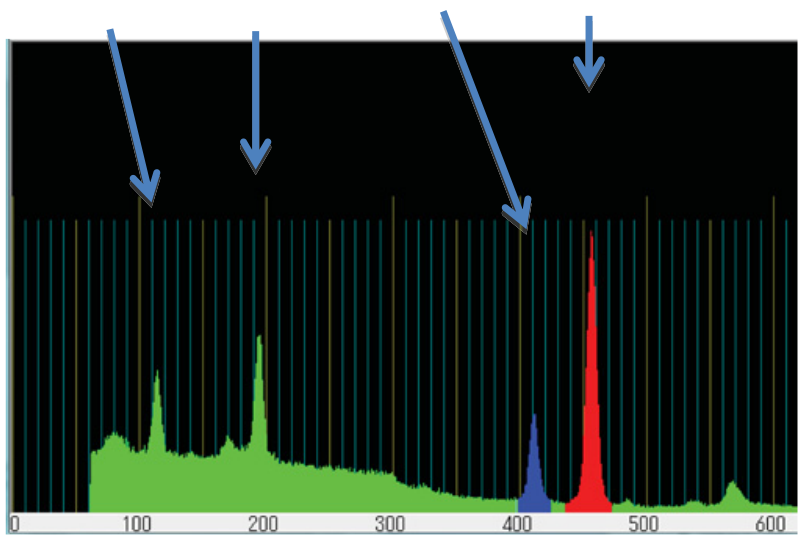

Figure 1. Gamma ray spectrum from a Li battery cathode made of $\mathrm{LiNi}_{0.8} \mathrm{Co}_{0.15} \mathrm{Al}_{0.05} \mathrm{O}_{2}$. The lines at $0.429 \mathrm{MeV}$ and $0.478 \mathrm{MeV}$ [10] are for $\mathrm{Li}^{7}\left(\mathrm{p} \cdot \mathrm{p}^{\prime} \gamma\right) \mathrm{Li}^{7}$ and ${ }^{7} \mathrm{Li}(\mathrm{p} . \mathrm{n} \gamma)^{7}$ Be respectively. The lines at $0.11 \mathrm{MeV}$ and $0.197 \mathrm{MeV}$ [12] are for ${ }^{9} \mathrm{~F}(\mathrm{p} . \mathrm{p} \gamma)^{19} \mathrm{~F}$, where $\mathrm{F}$ is included in the binder for pasting $\mathrm{LiNi}_{0.85} \mathrm{Co}_{0.15} \mathrm{Al}_{0.05} \mathrm{O}_{2}$ particles.

the relative fraction of $\mathrm{Li}$ in the anode like $\mathrm{Li}_{\mathrm{x}} \mathrm{Ni}_{0.8} \mathrm{Co}_{0.15} \mathrm{Al}_{0.05} \mathrm{O}_{2}$ where $\mathrm{x}(=0.75 \sim 1.0)$ is a variable during charge or discharge of the battery.

In this paper, we apply the PIGE and the PIXE diagnostics for studies of the Li-ion diffusion in $\mathrm{Li}$ ion battery positive electrode made by $\mathrm{Li}_{\mathrm{x}} \mathrm{Ni}_{0.8} \mathrm{Co}_{0.15} \mathrm{Al}_{0.05} \mathrm{O}_{2}(\mathrm{x}=0.75 \sim 1.0)$. This example demonstrates a potential application for laser produced ion beams. The proof of principle experiments for measuring the Li distributions in the Li-ion batteries were carried out by using the micro proton beam at the Takasaki Ion Accelerator for Advanced Radiation Application (TIARA), JAEA. As the results of the experiments, we found the requirements for applying the laser produced proton beam to the diagnostics of the Li ion behavior in Li ion battery.

\section{PIGE AND PIXE DIAGNOSTICS FOR LI AND NI}

The Li and $\mathrm{Ni}$ spatial distributions are simultaneously characterized for the positive electrode by $\mu-$ PIGE and $\mu-$ PIXE, respectively. Measurements were carried out at the microbeam line of TIARAJAEA. For the measurements a proton beam at an energy of $3.0 \mathrm{MeV}$ was used. The beam current was $300 \mathrm{pA}$. The total accumulated charge per map was around $0.48 \mu \mathrm{C}$. The beam diameter was $1.5 \mu \mathrm{m}$ and the total scan areas were $\leq 200 \times 200 \mu \mathrm{m}^{2}$. The scanning step was 128 of the total scan range, providing $128 \times 128$ space points for each image. Measurements were carried out in high vacuum at a pressure range of $10^{-5}$ mbar in order to achieve a good beam spatial resolution. The characteristic emitted $\gamma$ - and $\mathrm{X}$-rays were collected by a HPGe and by Li-doped Si detector located at $0^{\circ}$ and at $140^{\circ}$ to the beam direction, respectively. Under these conditions, typical measuring times were around 30 minutes.

The PIGE gamma ray spectrum for the $\mathrm{Li}^{7}\left(\mathrm{p} \cdot \mathrm{p}^{\prime} \gamma\right) \mathrm{Li}^{7}$ reaction $(\mathrm{E} \gamma=0.478 \mathrm{MeV})$, the ${ }^{7} \mathrm{Li}(\mathrm{p} . \mathrm{n} \gamma)^{7} \mathrm{Be}$ reaction $(\mathrm{E} \gamma=0.429 \mathrm{MeV})$ in the $\mathrm{Li}_{\mathrm{x}} \mathrm{Ni}_{0.8} \mathrm{Co}_{0.15} \mathrm{Al}_{0.05} \mathrm{O}_{2}$ positive electrode sample were shown in the Fig. 1. In the Fig. 1, the PIGE spectrum for the ${ }^{9} \mathrm{~F}(\mathrm{p} \cdot \mathrm{p} \gamma)^{19} \mathrm{~F}: \mathrm{E} \gamma=0.11 \mathrm{MeV}$ and $0.197 \mathrm{MeV}$ are also shown. The X-ray emission (PIXE) by the Ni(p, $\left.\mathrm{p}^{\prime} \gamma\right)$ Ni reaction $\left(\mathrm{E}_{\gamma}=7.48 \mathrm{keV}\right)$ were also taken. The cross section of $\mathrm{Li}^{7}\left(\mathrm{p} \cdot \mathrm{p}^{\prime} \gamma\right) \mathrm{Li}^{7}$ has the threshold of the proton beam energy at about $800 \mathrm{keV}$ and the resonance peak at $1 \mathrm{MeV}$. The expected gamma-ray yield is about $10^{8} / \mu$-Coulomb which is enough to achieve required resolution. On the other hand, the cross section for $\operatorname{Li}^{7}(\mathrm{p} . \mathrm{n} \gamma) \mathrm{Be}^{7}$ has the threshold at $1.8 \mathrm{MeV}$. 


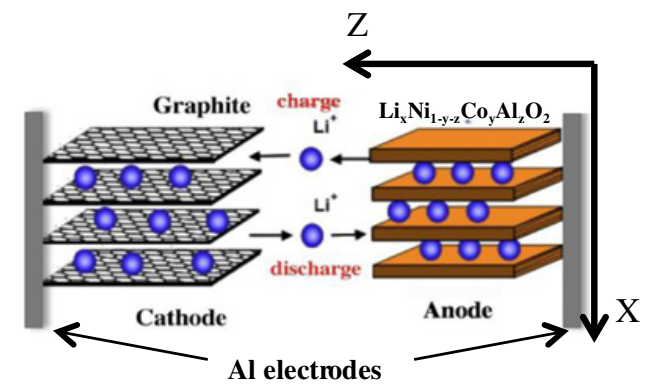

Figure 2. Li ions move from the anode to the cathode during charge and from the cathode to the anode during the discharge. $\mathrm{Li}$ ions are located between two lattice meshes of graphite or $\mathrm{Li}_{\mathrm{x}} \mathrm{Ni}_{0.8} \mathrm{Co}_{0.15} \mathrm{Al}_{0.05} \mathrm{O}_{2}$.

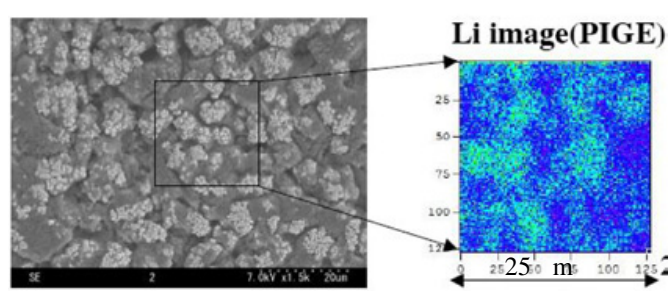

(a)

(b)

Figure 3. (a) A SEM image of a surface of Li battery cathode, (b) a Li PIGE image taken at TIARA, JAEA, Takasaki, Japan. The whole scale of the SEM is $100 \mu \mathrm{m} \times 100 \mu \mathrm{m}$ and the PIGE image scale is $25 \mu \mathrm{m} \times 25 \mu \mathrm{m}$. The dark blue areas indicate low $\mathrm{Li}$ concentration, where binder is dominant and sky blue areas indicate high Li concentration, where secondary particles of $\mathrm{Li}_{\mathrm{x}} \mathrm{Ni}_{0.8} \mathrm{Co}_{0.15} \mathrm{Al}_{0.05} \mathrm{O}_{2}$ exist. The size of the secondary particle is $10 \mu \mathrm{m} \sim 5 \mu \mathrm{m}$.

\section{PROTON BEAM NUCLEAR ANALYSIS OF ACTIVE MATERIALS IN THE LI ION BATTERY}

In the $\mathrm{Li}$ ion battery, it is important to see the $\mathrm{Li}$-ion behaviors in the electrodes during the charge and discharge processes. In Fig. 2, the $\mathrm{Li}$ ion motion during charge and discharge in the $\mathrm{Li}$ ion battery is shown. The anode contains $\mathrm{Li}_{\mathrm{x}} \mathrm{Ni}_{0.8} \mathrm{Co}_{0.15} \mathrm{Al}_{0.05} \mathrm{O}_{2}$ as an example and the cathode is made of $\mathrm{LiC}_{6}$ or Li metal as shown in Fig. 2. In the charging processes, $\mathrm{Li}$ ions in the anode de-intercalate into the electrolyte and intercalate into the cathode. During the discharge, $\mathrm{Li}$ ions de-intercalate from the cathode surface. The non-uniformity of the $\mathrm{Li}$ ion concentration in the anode is a critical issue for the Li battery performance.

The non-uniformity of the Li concentration depends upon charging rate, active materials, electrode structure and so on. In Fig. 2, the anode is made of an aluminum plate coated with a thin layer (30 $100 \mu \mathrm{m}$ thickness) containing fine particles of the active material $\left(\mathrm{Li}_{\mathrm{x}} \mathrm{Ni}_{0.8} \mathrm{Co}_{0.15} \mathrm{Al}_{0.05} \mathrm{O}_{2}\right.$ ). The surface of the positive electrode (anode) looks as Fig. 3(a) which is an image taken by SEM (Scanning electron microscope). A 2-3 MeV proton micro-beam irradiated the anode samples shown in Fig. 3(a). The beam was scanned precisely over the surface, and the spectral intensities of the $\gamma$ emission and the X-ray emission were recorded to obtain the PIGE and PIXE images, respectively. An example of the PIGE image for Li is shown in Fig. 3(b). The ratio of the PIGE signal and the PIXE signal yields the fraction of Li relative to Ni. Further more, the Fig. 3(b) shows the images of the fine particles (secondary particle) of $\mathrm{Li}_{\mathrm{x}} \mathrm{Ni}_{0.8} \mathrm{Co}_{0.15} \mathrm{Al}_{0.05} \mathrm{O}_{2}$, whose size is about 5-10 $\mu \mathrm{m}$. We also found that the PIGE and PIXE spatial resolutions are better than a few micro-meters for the proton beam of $1.5 \mu \mathrm{m}$ diameter.

\section{APPLICATION OF LASER PRODUCED PROTON BEAM FOR PIGE AND CONCLUDING REMARKS}

Let us consider the possibility of using laser produced proton beam for the above diagnostics. It is measured that laser produced ion beams have very low emittance in transverse direction [1] and they are 


\section{EPJ Web of Conferences}

laminar when the beam energy is separated by a spectrometer [8]. Actually, the emittance measured by T. Cowan et al. [1] is lower than $0.004 \mathrm{~mm} . \mathrm{mrad}$ although the energy is not monochromatic. Since the total beam fluence is required to be higher than $10^{13}$ for the present ion beam analysis, it is necessary to focus such a beam with appropriate focusing optics to a few micron diameter after the meter long propagation. So far, with a simple magnetic focusing, the experiments at the Max Born institute [8] demonstrated the focusing of a laser produced proton beam to a few $100 \mu$ m radius after meter long propagation. Therefore, it is necessary to develop a new focusing optics for focusing the laser produced proton beam to a few micro-meter diameter. For an example, the laser produced proton beam with the energy spread around a few $100 \mathrm{keV}$ should be focused. Note that the injected proton beam energy is not required to be strictly monochromatic for the PIGE imaging. So, the issue is how to focus a proton beam with a finite energy spread. One possible way is that we cut out a small part of a laser produced proton beam and focus it to micro-meter scale by the $\alpha$-magnet system achromatically. For realizing such a beam, further researches are required in future. As for the required proton flux for the above experiments, it is less than $500 \mathrm{pA}$ which means that the number of protons extracted from the laser ion source is $4 \times 10^{7}$ for $100 \mathrm{~Hz}$ operation. This will be $\sim 0.1 \%$ of the total flux of laser produced $\mathrm{MeV}$ proton for $10 \mathrm{~J}$ laser pulse. So, the requirement of the flux will be reasonable for the moderate laser system.

\section{CONCLUDING REMARK}

In addition to the results shown by Fig. 3, we cut the anode to see the depth Li distribution. The cross section surface was scanned by the proton beam. The results show that the Li distribution was significantly non-uniform for the rapidly charged thick anode sample (105 $\mu \mathrm{m}$ thickness). These experiments are the first time for the direct observation of the non-uniformity of the Li distribution. The detail of the measurements will be reported in another paper [12].

In summary, by the experiments with the proton micro-beam of the TIARA electrostatic accelerator, it is found that the scanning images of PIGE and PIXE of Li battery electrodes provide the micro-scale Li density distribution and it will be useful for the R\&D of Li battery materials. Since laser produced ions have very low transverse emittance $[1,2]$, the laser produced proton beam can be focused to the micro meter scale. So further investigations for applying laser driven ion beam to the Li battery nuclear material analysis are expected.

\section{References}

[1] T.E. Cowan, et al., Phys. Rev. Lett., 92, 204801 (2004)

[2] B.M. Hegelich, Nature 439, 441 (2006)

[3] K. Krushelnik et al., IEEE Trans. Plasma Sci. 28, 1184 (2000)

[4] S. V. Bulanov et al., Phys. Lett. A 299, 240 (2002)

[5] M. Roth et al., Phys. Rev. Lett. 86, 436 (2001)

[6] M. Borghesi et al., Phys. Rev. Lett. 92, 055003 (2004)

[7] P. Gibbon, Short pulse laser interactions with matter. $1^{\text {st }}$ ed. London: Imperial College Press, 2005

[8] S. Ter-Avetisyan, K. Mima, et al., Plasma Phys. and Cont. Fusion 51, 124046 (2009)

[9] Handbook of Modern Ion Beam Material Analysis, Edited by J.R. Tesmer and M. Natasi, July 1995, Material Research Society, Pittsburg, Pennsylvania, USA

[10] G. E. Cote, Nuclear Instruments and Methods B 66, 191-193 (1992)

[11] A. Climent-Font, A. Munoz-Martin, M.D. Ynsa, A. Zucchiatti, Nuclear Instruments and Methods B 266, 640-648 (2008)

[12] K. Mima, et al., NIMB (2012) to be published 